\title{
Creativity - Lost in Simplification?
}

\section{Mathias Benedek}

University of Graz, Austria

E-mail address: mathias.benedek@uni-graz.at

\author{
Emanuel Jauk \\ University of Graz, Austria \\ E-mail address: emanuel.jauk@uni-graz.at
}

ARTICLE INFO

\section{Keywords:}

Neuroscience of creativity

Cumulative science

Basic cognitive processes

\section{Article history:}

Received 7 November 2014

Received in revised form 19 December 2014

Accepted 20 December 2014

ISSN: 2354-0036

DOI: 10.15290/ctra.2014.01.02.06

\begin{abstract}
A B STRACT
The target article claims that creativity research is in crisis, which is associated with the excessive oversimplification employed in quantitative creativity research. We oppose this view by showing that lab measures of creative cognitive potential are valid with respect to real-life creativity and hence represent a valuable means of empirical creativity research. Neuroscientific research in particular, which is often viewed as a considerably artificial paradigm for the study of creativity, is a powerful complemental method to unveil basic cognitive mechanisms (e.g., attention and memory processes) involved in creative thought and to extend our understanding of the creating brain. Conceptual clarity and methodological rigor necessarily go along with simplification in natural science, which does not generally forfeit validity but rather facilitates the cumulative gain of dependable knowledge. This is particularly important for creativity research, a discipline that risks being seen as an immature science when it attempts to explain more than it actually can.
\end{abstract}

The target article by Glăveanu (2014) provides a comprehensive critique on the current state of affairs in creativity research. It is claimed that creativity research is in crisis. Key signs or reasons for this crisis are seen in the increasing fragmentation of topics (cf. Hennessey \& Amabile, 2010) with research focusing on very small units of analysis that may distort, rather than represent our understanding of creativity. Glăveanu calls in particular for a stronger contextualization of research, in order to better grasp the multi-faceted phenomenon of creativity in its contextual richness. Similar claims have been made previously. For example, Glover, Ronning and Reynolds (1989) were concerned that creativity research was a "'degenerating' research program" (p. XI), with no journals or organization providing leadership in the field. This situation led them to compile the first Handbook of Creativity, aiming to provide structure for the field and to point out potentially promising research agendas. Later reviews acknowledged the quantitative and qualitative progress in the field as indicated by relevant new journals, handbooks, and a committed APA division 10 , but still highlighted the importance of following the path of a cumulative science 
(e.g., Mumford, 2003; Simonton, 2000; Torrance, 2003).

\section{DO WE KILL CREATIVITY IN THE LAB?}

A general theme in the target article is that the quantification of creativity leads to an oversimplification, where the chosen units of analysis are so small that they no longer represent the original phenomenon in a meaningful way. So, do we kill creativity in the lab? This concern is for example, represented in the question "How can we ever relate back, in a meaningful way, people's capacity to generate ideas on demand, about things they might have no or little interest for, to their everyday activity and experience as creative agents?" (Glăveanu, 2014, p. 22). At first glance, this kind of argument sounds like a common objection to the natural science approach that is often espoused by fields like the humanities. Following this rationale, one might equally question whether it could ever make sense to study slimy snails to understand human memory or have electrons collide, to understand the cohesion of the universe. Speaking with artists, one sometimes observes similar reactions: the attempt to quantify creativity is viewed as an act of reductionist blasphemy - it just seems impossible to challenge the mystical aura of creativity, which is more readily associated with the kiss of the muse than any quantifiable trait or cognitive process.

However, the question posed by Glăveanu (2014) is actually not a theoretical, but an empirical one. And the simple answer is: We can. Evidence from cross-sectional and longitudinal studies, as well as meta-analytic evidence, shows consistently that divergent thinking ability predicts actual creative achievement (e.g., Jauk, Benedek \& Neubauer, 2014; Kim, 2008; Plucker, 1999; Torrance, 1993; but see also Baer, 1998). Moreover, divergent thinking ability has been found to be sensitive to differences in subgenres of specific domains (e.g. jazz music vs. classical music; Benedek, Borovnjak, Kruse-Weber, \& Neubauer, 2014) and even to performance skills within such a subgenre (i.e., improvisation performance in jazz musicians; Beaty et al., 2013). Of course, divergent thinking ability can only explain a limited part of the variance in creative achievement. But this is just what is to be expected according to multi-componential models of creativity, which assume interactions with other important traits (personality, cognitive ability and domainspecific expertise) as well as situational and environmental factors (Amabile, 1983; Eysenck, 1999; Simonton, 2014). All the more so, it seems astonishing that, even when disregarding all these important contextual factors, a domain-general cognitive ability, like divergent thinking, can still explain a relevant part of (domain-specific) real-life creative outcomes. It is hence safe to conclude that we do not kill creativity in the lab, but are dealing with a valid construct of high empirical value. Still, it is an ongoing process 
to question available measures (Beaty, Nusbaum, \& Silvia, 2014; Lee, Huggins, \& Therriault, 2014), refine them (e.g., Benedek, Mühlmann, Jauk, \& Neubauer, 2013; Plucker, Qian, \& Wang, 2011; Silvia et al., 2008), and look for other, potentially even more relevant ones. Based on solid evidence, we can then proceed to study more complex interactions between relevant factors (e.g., Jauk et al., 2014; King, Walker, \& Broyles, 1996), thus progressing from simple to increasingly complex models.

\section{THE CASE OF NEUROSCIENCE IN CREATIVITY RESEARCH}

We briefly want to address the case of neuroscience, which was regarded in the target article as a current fancy that cannot say much about creativity. In fact, this topic is sometimes viewed with scepticism even within the field of quantitative creativity research. Most of this research is focused on the process of creative idea generation and imagination, and hence aims at understanding how our brain forms novel concepts from previous experience. Assuming that this process may be essentially similar in the creative play of a child and in the creative insights of an artist or researcher, it arguably concerns the most fundamental and specific aspect of creative cognition. Furthermore, unveiling the brain mechanisms underlying such elementary processes of creative cognition represents a particularly exciting endeavour - at least for the cognitive neuroscientist.

In neuroscience research, creative idea generation is commonly implemented by means of basic divergent thinking tasks, but the processes under investigation are cut down even further to a duration of just a few seconds. This is probably bad news to those who believe that creativity can only be understood in terms of the experiential development of the individual, but goods news to those who think that a few minutes of idea generation involve a complex mixture of cognitive processes and strategies. It may not come as a surprise that early studies, which examined brain activation during long and highly diverse tasks such as story generation, visual design or musical improvisation, found little consistency in brain activation across studies (Arden, Chavez, Grazioplene, \& Jung, 2010; Dietrich \& Kanso, 2010). Neuroscientific studies generally require very precise assumptions on the involvement and timing of specific cognitive processes. Now, after focusing on more specific tasks and processes, the field has produced the first reliable findings (Vartanian et al., 2013).

We consider the neuroscientific approach to be a powerful complementary method in the investigation of cognitive processes that are not easily accessible via other common methods, such as tests and self-report. This includes questions on the role of attention and memory retrieval in creative thought (e.g., Benedek et al., 2014; Fink \& Benedek, 2014). Moreover, it enables us to extend our understanding of the general functioning 
of our brains to the important realm of creative cognition. For example, neuroscience research has helped to qualify the popular notion that creativity is "located" in the "associative-intuitive" right hemisphere and demonstrated that creative thought involves many ordinary and few extraordinary processes. But, it is just one method and its ultimate value will depend on the strength of the theorizing involved in the design of studies and the interpretation of findings (Abraham, 2013).

\section{THE ARDUOUS PATH OF CUMULATIVE SCIENCE}

With a phenomenon like creativity, which is highly complex and not well understood, simplification is a common approach in order to identify tractable problems. Solving those problems is the way of "normal science" leading to the accumulation of dependable knowledge (Kuhn, 1962). This particularly involves the establishment of replicable effects, which requires asking the same "old questions" again and again. Step by step, available models become expanded or revised in order to accommodate new and conflicting findings, following the path of cumulative science (Mischel, 2005; cf. Vartanian, 2014). This process cannot be easily side-stepped by immediately jumping to new, grand theories (Karwowski, 2012), unless those theories can be shown to better explain and integrate available evidence. Otherwise, we run the risk of just rewriting the language of creativity without contributing to an increased understanding, but eventually rather to further fragmentation of research. This may also apply to the aim of increasing contextualization in research. Such contextualization is informative, as long as it is specific in precisely describing the contexts and factors that should or should not lead to certain observations. It is, however, not helpful when contextualization takes the form of an exercise in compiling extensive lists of potentially relevant contexts and factors without further specificity, as this might forfeit falsifiability. The path of cumulative science most likely involves a lot of "dirty" empirical work that should not be despised for not tackling all questions at once.

We agree that in this process, it is important to remain aware that research is typically focused on a specific part of the puzzle, which also should be specified when describing research. Moreover, it is certainly advisable to look beyond one's own nose from time to time, in order not to lose track of the bigger picture. Along these lines, we propose that one particularly fruitful avenue for future research might be to examine whether concepts that are thought to be specific to creativity research can be re-thought in terms of welldefined cognitive constructs, as established in cognitive science. This way, we might eventually end up understanding, for example, creative idea generation as goal-directed, multiple-constrained memory search process. Would we then have killed creativity after 
all? At least, further integration into general theories of human cognition might kill some illusions about its peculiarity - an important step along the path of cumulative science.

\section{REFERENCES}

Abraham, A. (2013). The promises and perils of the neuroscience of creativity. Frontiers in Human Neuroscience, 7, 246.

Abraham, A., Pieritz, K., Thybush, K., Rutter, B., Kröger, S., Schweckendiek, J., Stark, R., Windmann, S., \& Hermann, C. (2012). Creativity and the brain: Uncovering the neural signature of conceptual expansion. Neuropsychologia, 50, 1906-1917.

Amabile, T.M. (1983). The social psychology of creativity: A componential conceptualization. Journal of Personality and Social Psychology, 45, 357-376.

Arden, R., Chavez, R.S., Grazioplene, R., \& Jung, R.E. (2010). Neuroimaging creativity: A psychometric view. Behavioral Brain Research, 214, 143-156.

Baer, J. (1998). The case for domain specificity of creativity. Creativity Research Journal, 11, 173-177.

Beaty, R.E., Smeekens, B.A., Silvia, P.J., Hodges, D.A., \& Kane, M.J. (2013). A first look at the role of domain-general cognitive and creative abilities in jazz improvisation. Psychomusicology: Music, Mind, and Brain, 23, 262-268.

Beaty, R.E., Nusbaum, E.C., \& Silvia, P.J. (2014). Does insight problem solving predict real-world creativity? Psychology of Aesthetics, Creativity, and the Arts, 8, 287-292.

Benedek, M., Borovnjak, B., Neubauer, A.C., \& Kruse-Weber, S. (2014). Creativity and personality in classical, jazz and folk musicians. Personality and Individual Differences, 63, 117-121.

Benedek, M., Jauk, E., Fink, A., Koschutnig, K., Reishofer, G., Ebner, F., \& Neubauer, A.C. (2014). To create or to recall? Neural mechanisms underlying the generation of creative new ideas. Neurolmage, 88, 125-133.

Benedek, M., Mühlmann, C., Jauk, E., \& Neubauer, A.C. (2013). Assessment of Divergent Thinking by means of the Subjective Top-Scoring Method: Effects of the Number of Top-Ideas and Time-on-Task on Reliability and Validity. Psychology of Aesthetics, Creativity, and the Arts, 7, 341-349.

Dietrich, A. \& Kanso, R. (2010). A Review of EEG, ERP, and Neuroimaging Studies of Creativity and Insight. Psychological Bulletin, 136, 822-848.

Eysenck, H.J. (1995). Genius. The natural history of creativity. Cambridge, UK: Cambridge University Press.

Fink, A. \& Benedek, M. (2014). EEG alpha power and creative ideation. Neuroscience and Biobehavioral Reviews, 44, 111-123. 
Glăveanu, V.P. (2014). The psychology of creativity: a critical reading. Creativity: Theories - Research - Applications, 1, 10-32, DOI: 10.15290/ctra.2014.01.01.02.

Glover, J.A., Ronning, R.R. \& Reynolds, C.R. (1989). Handbook of creativity. New York: Plenum Press.

Hennesey, B.A. \& Amabile, T.M. (2010). Creativity. Annual Review of Psychology, 61, 569-598.

Jauk, E., Benedek, M. \& Neubauer, A.C. (2014). The Road to Creative Achievement: A Latent Variable Model of Ability and Personality Predictors. European Journal of Personality, 28, 95-105.

Karwowski, M. (2012). Middle and grand theorizing in the psychology of creativity. Creativity and Leisure. An Intercultural and Cross-disciplinary Journal, 1, 109-115.

Kim, K.H. (2008). Meta-analyses of the relationship of creative achievement to both IQ and divergent thinking test scores. Journal of Creative Behavior, 42, 106-130.

King, L.A., Walker, L.M., \& Broyles, S.J. (1996). Creativity and the five-factor model. Journal of Research in Personality, 30, 189-203.

Kuhn, T.S. (1962). The structure of scientific revolutions. Chicago: University of Chicago Press.

Lee, C.S., Huggins, A.C., \& Therriault, D.J. (2014). A measure of creativity or intelligence? Examining internal and external structure validity evidence of the Remote Associates Test. Psychology of Aesthetics, Creativity, and the Arts, 8, 446-460.

Mischel, W. (2005). Alternative futures for our science. APS Observer, 18(3). Retrieved from http://www.psychologicalscience.org/index.php/publications/observer/2005/march -05/alternative-futures-for-ourscience.html

Mumford, M.D. (2003). Where have we been, where are we going? Taking stock in creativity research. Creativity Research Journal, 15, 107-120.

Plucker, J.A. (1999). Is the proof in the pudding? Reanalyses of Torrance's (1958 to present) longitudinal data. Creativity Research Journal, 12, 103-114.

Plucker, J.A., Qian, M. \& Wang, S. (2011). Is originality in the eye of the beholder? Comparison of scoring techniques in the assessment of divergent thinking. The Journal of Creative Behavior, 45, 1-22.

Silvia, P.J., Winterstein, B.B., Willse, J.T., Barona, C.M., Cram, J.T., Hess, K.I., \& Richard, C.A. (2008). Assessing creativity with divergent thinking tasks: Exploring the reliability and validity of new subjective scoring methods. Psychology of Aesthetics, Creativity, and the Arts, 2, 68-85. 
Simonton, D.K. (2000). Creativity. Cognitive, personal, developmental, and social aspects. American Psychologist, 55, 151-158.

Simonton, D.K. (2014). Creative performance, expertise acquisition, individual differences, and developmental antecedents: An integrative research agenda. Intelligence, 42, 66-73.

Torrance, E.P. (1993). The beyonders in a thirty year longitudinal study of creativity achievement. Roeper Review, 15, 131-135.

Torrance, E.P. (2003). The millenium: Time for looking forward and looking back. The Journal of Secondary Gifted Education, 15, 6-12.

Vartanian, O. (2014). Toward a cumulative psychological science of aesthetics, creativity, and the arts. Psychology of Aesthetics, Creativity, and the Arts, 8, 15-17.

Vartanian, O., Bristaol, A.S., \& Kaufman, J.C. (Eds.) (2013). Neuroscience of creativity. Cambridge, MA: MIT Press.

Corresponding author at: Mathias Benedek, Department of Psychology, University of Graz, Maiffredygasse 12b, A-8010 Graz

E-mail: mathias.benedek@uni-graz.at

Corresponding author at: Emanuel Jauk, Department of Psychology, University of Graz, Maiffredygasse 12b, A-8010 Graz

E-mail: emanuel.jauk@uni-graz.at 